\title{
WFUMB 2019 Melbourne, Australia
}

\section{Speakers Tom Marwick and Carlos Martinoli announced, and the Young Investigators' Award}

Over 120 ultrasound experts

35 international speakers

Don't miss out!

\section{Keynote speaker - Welcome Professor Carlo Martinoli}

ASUM are proud to sponsor Professor Carlo Martinoli, known as one of the most prominent teachers in musculoskeletal ultrasound, as a keynote to present in the MSK and Rheumatology sessions at WFUMB 2019.

Prof. Martinoli is the author of a preeminent textbook on Musculoskeletal Ultrasound and has published over 230 scientific articles in international peer reviewed medical journals.

A renowned speaker, Prof. Martinoli has held over one thousand invited lectures at international courses or congresses; and is the founder of the International Society of Peripheral Neurophysiological Imaging (ISPNI), a multidisciplinary society that aims to forward global education and research in peripheral nerve imaging.

Prof. Martinoli's presentations will include:

- Ultrasound of the rotator cuff interval and biceps tendon

- Ultrasound of the Anterolateral Hip'

- Ultrasound of nerve tumours and tumour-like masses

Register for early bird tickets!

\section{WFUMB Young Investigators' Award}

The $\$ 2000$ USD WFUMB Young Investigators' Award will be presented at WFUMB 2019.

From oral and poster abstracts submissions will be shortlisted abstracts from those under 35 years of age, to be invited to present at a dedicated session at the Congress, and may also be invited to present in relative streams

\section{Keynote speaker - Welcome Professor Thomas Marwick, MBBS, PhD, MPH}

Professor Tom Marwick, MBBS, PhD, MPH, will open the Cardiac stream of the WFUMB 2019 Congress on Sunday 8 September in a session titled "Echocardiography: The Big Picture". This presentation will explore QC in the echo lab; guidelines in the real world; improving training and accreditation for cardiologists in Australia; and the global challenge of early detection of RHD.

Prof. Marwick completed training in medicine and cardiology in Australia, before undertaking an Imaging Fellowship at Cleveland Clinic, a PhD at the University of Louvain, Belgium and a Masters in Public Health at Harvard. Currently the Director of Baker Heart and Diabetes Institute, Prof. Marwick has divided his career mostly between Australia and the USA.
One of the initiators of stress echocardiography, Prof. Marwick contributions to the industry have been significant including contributions to the prognostic evidence underlying cardiovascular imaging; clinical research and research training; and supervision of approximately 30 research higher degree students, including 22 completed PhDs.

The author of over 650 published papers, reviews, chapters and editorials and recipient of more than 50 significant research grants and several awards, Prof. Marwick's main current research interests relate to the detection of early cardiovascular disease and cost-effective application of cardiac imaging techniques for treatment selection and monitoring.

Register for early bird tickets!

\section{Book your tickets and head to Melbourne for a massive meeting! You're invited...}

Assoc. Prof George Condous, ASUM Board of Directors Member and WFUMB Global Scientific Committee Convenor, looks forward to seeing you at WFUMB 2019 for the world congress in ultrasound.

Prof Condous reminds you to get your papers in, get your abstracts in, and book your tickets!

WFUMB 2019, Melbourne, 6 - 9 September 2019.

www.wfumb2019.org 